must be eminent, or they would not have been elected to our chair, and these on this occasion happen to represent the three divisions of the United Kingdom. So there need not be any alarm. I suggest that the naming of the committee be left to the three Presidents.

Dr. J. G. Smith : I should like to add the General Secretary to the list.

Dr. Collins : I second that.

Dr. STODDART : I second Dr. Newington's proposal.

Carried with the addition of Dr. Bond's name.

Dr. Hayes Newington: Then there is the question of the size of the committee. It is very important to know what the size will be.

The President : We shall be glad to have any guidance you may give us.

Dr. StodDarT: Would it be unusual to suggest that the gentleman who pro-

posed the motion should be on the Selection Committee?

The President : Individuals had better not be named.

Dr. Middemass : I suppose there will be a certain number of assistant medical officers on it?

The President : Yes.

Dr. Collins: I think not less than half the committee should be assistant medical officers.

The President : You may rely upon it that the assistant medical officers shall be properly represented.

The President then read out the terms of Dr. Pierce's amended resolution: "This meeting strongly urges the importance of necessary facilities being provided to assistant medical officers of asylums for obtaining the Diploma in Psychological Medicine or other Special qualification. This question is referred to the Educational Committee in order to give effect to the expressions of opinion at this meeting."

The amended resolution having been accepted, the meeting then terminated.

\title{
THE MEDICO-PSYCHOLOGICAL ASSOCIATION OF GREAT BRITAIN
}

\section{AND IRELAND.}

The Quarterly Mreting was held at the Rooms of the Medical Society of London, on Tuesday, November 2 Ist, 1911, under the Presidency of Dr. W. R. Dawson.

The minutes of the last meeting having appeared in the Journal were taken as read, and were confirmed.

The President (Dr. W. R. Dawson) and the following sixty-one members were present : T. Stewart Adair, G. F. Barham, Fletcher Beach, C. H. Bond, David Bower, A. Boycot, R. B. Campbell, J. Carswell, James Chambers, W. C. Clapham, M. A. Collins, W. E. Collier, Geoffrey Clarke, Maurice Craig, G. Cribb, A. W. Daniel, J. Dixon, Sir Horatio Donkin, C. Dove, E. L. Dove, Thos. Drapes, J. H. Earls, Sam. Elgee, C. T. Ewart, J. J. Fitzgerald, H. Haynes, David Hunter, J. B. Hyslop, G. Johnston, Robert Jones, John Keay, H. Kerr, R. LangdonDown, L. Legge, H. Wolseley-Lewis, J. R. Lord, T. W. McDowall, H. J. Mackenzie, C. Mercier, Jas. Middlemass, Alf. Miller, W. F. Nelis, H. Hayes Newington, M. Eden Paul, J. E. Porter-Phillips, J. F. Powell, Wm. Rawes, Geo. M. Robertson, Geo. H. Savage, J. G. Secretan, G. E. Shuttleworth, R. Percy Smith, J. B. Spence, T. E. K. Stansfield, R. H. Steen, R. J. Stilwell, H. H. B. Stoddart, J. Tattersall, J. D. Thomas, D. G. Thomson, Wm. Vincent.

Visitors at the above were: Drs. J. M. Sargeant, C. F. A. Vivian, W. Watson, and J. C. Wootton.

Members of the Royal Society of Medicine, Obstetrical Section, at above: W. H. Bailey, J. Barris, H. Briggs, J. F. Briscoe, Hayden Brown, John Cahill, E. O. Croft, F. G. Crookshank, H. P. Dimmock, T. W. Eden, W. S. A. Griffiths, J. P. Hedley, G. E. Herman, H. Macnaughton Jones, Amand Routh (President), A. W. Russell, Mary Scharlieb, Heywood Smith, J. H. Targett, W. W. H. Tate, May Thorne, Ethel Vaughan-Sawyer, Jane Walker, J. A. Willett, Robt. Wise.

Visitors at above: Drs. Emily MacRedy and C. StA. Vivian. 
The Late Dr. G. Fielding Blandford.

The President said his first duty that day was a sad one, namely, to allude to the death of Dr. George Fielding Blandford, one of the oldest members, and a former President, of the Association. His figure was a familiar one at their meetings; up till two years ago he took a deep interest in everything which concerned the welfare of the insane, and his opinions always commanded the respect of his audience. He was well known to be a warm-hearted friend. His death took place at the time of year when most medical men were away on their holiday, but his funeral was attended by some of their officials, and a funeral wreath from the Association was sent. He proposed that a vote of condolence be sent by the General Secretary to Dr. Blandford's family. This was carried by the members rising in silence.

\section{The Late Dr. Murray Lindsay.}

Another very old member of the profession who had gone was Dr. Murray Lindsay, who had also been President of the Association. No doubt many of those present would remember the successful meeting at Buxton in 1893 , which was held in the year of Dr. Lindsay's presidency. Dr. Lindsay took a very keen interest in the pension question, and although ill.health did not allow him to be present at many of the recent meetings of the Association, he felt sure that the news of his decease would be received with regret by all the members of the Association. The President moved that a similar vote of condolence be sent to his relatives. This also was carried by the members rising in silence.

\section{The Care and Control of the Faeble-minded.}

The President mentioned that a letter had been received from the National Association for the Care and Control of the Feeble-minded relative to proposed legislation for that class of defectives, and stated that a resolution had been passed by the Council on this subject as follows: "That this Association is strongly impressed with the great danger to the State which results from the absence of any power to control the feeble-minded, and heartily supports the principle of granting powers of care and control." Not having the terms of the Bill before them the Council could not criticise it, but they felt that they would like to strengthen the hands of the Associations concerned, and they had further referred the matter to the Parliamentary Committee.

\section{The Diplomas in Psychological Mrdicine.}

The President stated, for the benefit of such as had not been present on the previous day, that a Special Meeting had been held in that room, at which the subject of the newly created Diplomas in Psychological Medicine in relation to existing medical officers was discussed, and also the general subject of the status of the assistant medical officers of asylums. A great many interesting speeches were heard, as well as two very valuable papers from Dr. Rows and Dr. Orr. After a prolonged discussion the opinions of the meeting were finally crystallised in two resolutions. One was proposed by Dr. Craig as follows: "That this meeting strongly urges the importance of necessary facilitios boing provided to assistant medical officers of asylums for obtaining the Diploma in Psychological Tedicine or other apecial qualification. This question is referred to the Bducational Committee in order to give effect to the expressions of opinion at this meeting." That came before the Committee that morning. The second resolution was proposed by Dr. Bernard Hart as follows: "That a Committoe be formed to consider the status of paychiatry as a profession in Great Britain and Ireland, and the reforms necessary in the oducetion and conditions of service of assistant medical officers." The appointment of that Committee was entrusted to the ExPresident, the President-Elect, and himself, with the addition of the General Secretary. Steps would be taken immediately in accordance with the resolution. 
The following candidates for ordinary membership were ballotted for and unanimously elected, Dr. Collins and Dr. Hunter acting as scrutineers.

Ellerton, John Frederick Heise, M.D.Brux., M.R.C.S.Eng., L.R.C.P.Edin., 8, Leam Terrace, Leamington Spa. (Proposed by W. Douglas, R. Percy Smith, and Alfred Miller.)

Gavin, Lawrence, M.B., Ch.B.Edin. L.R.C.P. \& S. Edin., L.R.F.P.S.Glas. Assistant Medical Officer, London County Asylum, Horton, Epsom. (Proposed by John R. Lord, David Ogilvy, and Samuel Elgee.)

Hughes, Frank Percival, M.B.,B.S.Lond., M.R.C.S., L.R.C.P., The Grove, Pinner, Middlesex. (Proposed by W. H. B. Stoddart, R. P. Smith, and Maurice Craig.)

MacCarthy, Hilgrove Leslie, M.A., M.D.Dubl., D.P.H.Oxon., Park Hospital (M.A.B.), Lewisham, S.E. (Proposed by J. G. Porter Phillips, G. F. Barham, and C. Hubert Bond.)

Robson, Lieut. Hubert Alan Hirst, I.M.S., M.R.C.S., L.R.C.P.Lond., care of Messrs. Grindlay Groom, Bombay. (Proposed by R. Percy Smith, G. F. Barham, and C. Hubert Bond.)

Sargeant, John Noel, M.B., B.S.Lond., M.R.C.S., L.R.C.P., Medical Superintendent, Newlands House, Tooting Bec Road, S.W. (Proposed by R. Percy Smith, Frank R. King, and James Chambers.)

A very interesting and valuable paper was read by Dr. Georfrey Clarke on "Sterilisation from a Eugenic Standpoint." The paper was largely based upon a laborious analysis of the clinical records at Long-Grove Asylum. It was followed by a discussion in which Drs. Stansfield, Eden Paul, Wolseley-Lewis, BoyCott, M. A. Collins, Bond, D. G. Thomson, Soutar, Hayes Newington, G. M. Robertson, and the President took part, and to which Dr. Clarke replied.

The Association then resolved itself into a joint session with the Section of Gynæcology and Obstetrics of the Royal Society of Medicine, Dr. Dawson gracefully surrendering the Chair in favour of Dr. Amand Routh, the President of the Section. The subject for debate was " Amenorrhoal Insanity," and it was introduced in a very comprehensive paper by Dr. C. T. EwarT.

The paper led to an animated and interesting discussion, in which Drs. Robert Jones, Macnaughton Jones, Percy Smith, Russell (Glasgow), Walter Griffith, Hayden Brown, Stoddart, and the President of the MedicoPsychological Association took part.

Dr. Amand Routh congratulated the joint meeting on the discussion. It was known, he said, that menstruation was due to something, some chemical agent, which accumulated in the blood, reached a certain pitch, and encouraged the uterus and the ovaries to become active. The change in the blood was due to the formation of an excess of calcium, and the first act of the menstruating uterus was to excrete a large quantity of lime salts, which lowered the lime content of the blood and encouraged hæmorrhage from the uterus. Amenorrhcea showed that the products which ought to be in the blood in order to encourage menstruation were absent. So probably amenorrhoea meant that the patient suffered from a diminution of some substances and an excess of others.

Dr. EWART replied, but did not attempt to traverse all the arguments which had been adduced, owing to the pressure of time.

The members subsequently dined together at the Café Monico.

\section{SOUTH-EASTERN DIVISION.}

The Autumn Meeting of the South-Eastern Division was held, by the courtesy of Dr. Hugh Kerr, at the Bucks County Asylum, Stone, Aylesbury, on Wednesday, October 4th, 1911. Among those present were-Drs. H. M. Baker, Fletcher Beach, David Bower, T. O'C. Donelan, F. W. Edridge-Green, Francis H. Edwards, Hugh Kerr, J. Grimmond Smith, T. E. K. Stansfield, John Turner, F. Watson, and David Hunter (Hon. Secretary).

Visitors: The Rev. E. C. Stukeley and Dr. J. P. Westrup.

Letters regretting absence were received from Drs. Bond, Greenlees, Haynes, 